University of Wollongong

Research Online

Faculty of Engineering and Information

Faculty of Engineering and Information

Sciences - Papers: Part A

Sciences

$1-1-2015$

\title{
Laboratory determination of coefficient of consolidation from pore water pressure measurement
}

J S. Vinod

University of Wollongong, vinod@uow.edu.au

A Sridharan

Indian Institute of Science

Follow this and additional works at: https://ro.uow.edu.au/eispapers

Part of the Engineering Commons, and the Science and Technology Studies Commons

Research Online is the open access institutional repository for the University of Wollongong. For further information contact the UOW Library: research-pubs@uow.edu.au 


\title{
Laboratory determination of coefficient of consolidation from pore water pressure measurement
}

\author{
Abstract \\ ICE Publishing: all rights reserved. In the recent past, many studies have been carried out on the \\ determination of coefficient of consolidation (cv) from the time (t)-deformation (d) data obtained from \\ conventional consolidation tests. Several researchers have also proposed different curve fitting \\ procedures for determining $\mathrm{cv}$ from the $\mathrm{t}-\mathrm{d}$ data. It is anticipated that the $\mathrm{cv}$ values obtained from the $\mathrm{t}-\mathrm{d}$ \\ data may be influenced by initial and secondary compressions. Nevertheless, the pore water pressure \\ data measured during the consolidation process will be independent of initial and secondary \\ compressions. In this study, the conventional Asaoka (1978) method is extended to evaluate cv and end- \\ of-primary (EOP) consolidation from the pore water pressure data measured from laboratory \\ experiments. Laboratory experiments were carried out on the modified one-dimensional consolidation \\ apparatus on different remoulded clay samples measuring pore water pressure during the consolidation \\ process. The cv and EOP computed from the proposed approach have been compared with the results of \\ the $t-d$ data and found to be in good agreement.

\section{Disciplines} \\ Engineering | Science and Technology Studies

\section{Publication Details} \\ Vinod, J. S. \& Sridharan, A. (2015). Laboratory determination of coefficient of consolidation from pore \\ water pressure measurement. Geotechnique Letters, 5 (4), 294-298.
}




\title{
Laboratory determination of coefficient of consolidation from pore water pressure measurement
}

\author{
J. S. VINOD* and A. SRIDHARAN†
}

In the recent past, many studies have been carried out on the determination of coefficient of consolidation $\left(c_{v}\right)$ from the time $(t)$-deformation $(d)$ data obtained from conventional consolidation tests. Several researchers have also proposed different curve fitting procedures for determining $c_{v}$ from the $t-d$ data. It is anticipated that the $c_{v}$ values obtained from the $t-d$ data may be influenced by initial and secondary compressions. Nevertheless, the pore water pressure data measured during the consolidation process will be independent of initial and secondary compressions. In this study, the conventional Asaoka (1978) method is extended to evaluate $c_{v}$ and end-of-primary (EOP) consolidation from the pore water pressure data measured from laboratory experiments. Laboratory experiments were carried out on the modified one-dimensional consolidation apparatus on different remoulded clay samples measuring pore water pressure during the consolidation process. The $c_{v}$ and EOP computed from the proposed approach have been compared with the results of the $t-d$ data and found to be in good agreement.

KEYWORDS: clays; consolidation; deformation

ICE Publishing: all rights reserved

\section{NOTATION}

$c_{\mathrm{V}}$ coefficient of consolidation

$d$ deformation

$d_{100}$ deformation at EOP

$H$ drainage path

$s_{j} \quad$ settlement at time $j$

$s_{j+1} \quad$ settlement at any time $j+1$

$T$ time factor

$t$ time

$U_{z}$ degree of consolidation

$u$ pore water pressure

$u_{0} \quad$ initial pore water pressure

$u_{100} \quad$ pore water pressure at end of primary

$u_{j} \quad$ pore water pressure at any time $j$

$u_{j+1} \quad$ pore water pressure at any time $j+1$

\section{INTRODUCTION}

A reasonably good estimate on the coefficient of consolidation $\left(c_{\mathrm{v}}\right)$ is required for evaluating the rate of deformation/ settlement of a clayey soil due to the overburden pressure. The classical work of Terzaghi's theory of one-dimensional consolidation forms the basis for most of the methods available for the determination of $c_{\mathrm{v}}$. The coefficient of consolidation is generally estimated from the timedeformation $(t-d)$ data obtained from the one-dimensional consolidation tests. Several research studies have been carried out on the determination of $c_{\mathrm{v}}$ from the $t-d$ data based on the curve fitting procedures (e.g. Casagrande \& Fadum, 1940; Parkin, 1978; Sridharan et al., 1987; Robinson \& Allam, 1996; Sridharan \& Prakash, 1993, 1997, 1998; Taylor, 1948, to name a few). The curve fitting

Manuscript received 7 September 2015; first decision 12 November 2015; accepted 13 November 2015.

Published online at www.geotechniqueletters.com on 9 December 2015.

*School of Civil, Mining \& Environmental Engineering, University of Wollongong, Wollongong, NSW, Australia.

†Indian National Science Academy, Delhi, India; Indian Institute of Science, Bangalore, India. procedures basically utilise the characteristic features of the theoretical degree of consolidation $(U)$ and time factor $(T)$ relationship with the laboratory $t-d$ data. It is important to note that the $c_{\mathrm{v}}$ determined from the experimental $t-d$ data may be influenced by initial (immediately on the application of load) and secondary compressions (Sridharan et al., 1995). Sridharan et al. (1995) highlighted the fact that initial compression increases and secondary compression decreases the value of $c_{\mathrm{v}}$ computed based on the $t-d$ data. However, Tan \& Chew (1996) have shown that the rectangular hyperbola method (Sridharan et al., 1987) and the Asaoka (1978) method will give very good predictions for $c_{\mathrm{v}}$ and end of primary (EOP) and is a useful tool in monitoring consolidation in the field. Recently, Prakash et al. (2013) highlighted that Asaoka (1978) method is a very simple approach for computing $c_{\mathrm{v}}$ and (EOP) compression from laboratory deformation data. Alternately, Taylor (1948) has shown a reasonable agreement on the pore water pressure measured in the field and laboratory during consolidation. Lot of laboratory experimental studies have been carried out, in the past, on the measurement of pore water pressure during consolidation (e.g. Whitman et al., 1961; Gibson, 1963; Northey \& Thomas, 1965; Sonpal \& Katti, 1973; Robinson, 1999; Robinson \& Soundara, 2008). Most of the studies were carried out by mounting a pore water pressure measurement device at the base of the consolidation apparatus. However, the compliance of the pore pressure measuring device has significant influence on the pore water pressure data obtained from these tests. Moreover, an analysis of the laboratory-measured pore pressure data highlighted that the $c_{\mathrm{v}}$ values obtained from the pore water pressure may differ significantly compared with settlement analysis (Olson, 1986).

Although many methods are available for computing $c_{\mathrm{V}}$ from the $t-d$ data, only very few methods can be found in the literature on the determination of $c_{\mathrm{V}}$ using the pore water pressure data (e.g. Robinson, 1999; Robinson \& Soundara, 2008). Robinson (1999) has proposed a graphical procedure for determining $c_{\mathrm{v}}$ from $U$-compression $(\delta)-\sqrt{t}$ curve. A linear relationship observed between pore water pressure and 
compression was adopted for computing $c_{\mathrm{v}}$. Robinson \& Soundara (2008) developed a curve fitting procedure for computing $c_{\mathrm{v}}$ from the degree of dissipation at the base of the sample $\left(U_{\mathrm{b}}\right)$ against $\log t$ relationship and highlighted that this method is less influenced by secondary compression. In this study, conventional Asaoka (1978) method has been extended to compute the value of $c_{\mathrm{v}}$ from the pore water pressure data.

\section{THEORETICAL CONSIDERATION}

Asaoka (1978) proposed a graphical approach for estimating the value of $c_{\mathrm{v}}$ and EOP compression based on Mikasa's consolidation theory. The mathematical deduction for the method is not very simple (Mesri \& Huvaj-Sarihan, 2009); however, the graphical approach is simple and widely used by practising engineers. The procedure consists of plotting settlement/deformation data taken at regular intervals against the elapsed time. More details on the procedure for evaluating $c_{\mathrm{v}}$ based on the settlement data can be found elsewhere (e.g. Asaoka, 1978; Tan \& Chew, 1996; Mesri \& Huvaj-Sarihan, 2009; Prakash et al., 2013). Recently, Mesri \& Huvaj-Sarihan (2009) proposed a simple mathematical deduction for Asaoka's (1978) method for the settlement data obtained from one-dimensional consolidation test. This mathematical deduction has been extended, in this study, to consider the pore water pressure measured at the base of the sample.

The relationship between the degree of consolidation and pore water pressure at a distance $z$ at any time $t$ is given by

$$
U_{z}=\frac{u_{0}-u_{j}}{u_{0}}
$$

where $U_{z}$ is the average degree of consolidation; $u_{0}$ is the initial pore water pressure and $u_{j}$ is the pore water pressure at any time $j$.

The relationship between the degree of consolidation $\left(U_{z}\right)$ against time $(t)$ proposed by Terzaghi for linear distribution of initial excess pore water pressure for $U_{z}>50 \%$ can be expressed as

$$
U_{z}=1-\frac{8}{\pi^{2}} \exp \left(\frac{-\pi^{2} c_{\mathrm{v}} t}{4 H^{2}}\right)
$$

and

$$
T=\frac{c_{\mathrm{v}} t}{H^{2}}
$$

where $T$ is the time factor, $c_{\mathrm{v}}$ the coefficient of consolidation and $H$ is the drainage path.

Substituting equation (1) into equation (2)

$$
\frac{u_{0}-u_{j}}{u_{0}}=1-\frac{8}{\pi^{2}} \exp \left(\frac{-\pi^{2} c_{\mathrm{v}} t}{4 H^{2}}\right)
$$

Equation (3) can be rewritten as

$$
\frac{u_{j}}{u_{0}}=\frac{8}{\pi^{2}} \exp \left(\frac{-\pi^{2} c_{\mathrm{v}} t}{4 H^{2}}\right)
$$

Consider settlements at elapsed time $t_{j}$ and $t_{j}+1$ and let $A=-\pi^{2} c_{\mathrm{v}} / 4 H^{2}$, then

$$
\frac{u_{j}}{u_{0}}=\frac{8}{\pi^{2}} \exp \left(A t_{j}\right)
$$

and

$$
\frac{u_{j+1}}{u_{0}}=\frac{8}{\pi^{2}} \exp \left(A t_{j+1}\right)
$$

Dividing equation (6) by equation (5), one can get

$$
\begin{aligned}
& \frac{u_{j+1}}{u_{j}}=\exp \left[A\left(t_{j+1}-t_{j}\right)\right] \\
& \text { Let } t_{j+1}-t_{j}=\Delta t \text { constant and } A^{\prime}=\exp (A \Delta t) \\
& u_{j+1}=u_{j} A^{\prime}
\end{aligned}
$$

It is evident from equation (8) that a plot of $u_{j+1}$ against $u_{j}$ should be a straight line having a slope $A^{\prime}$ and when $u_{j+1}=u_{j}$ this will intersect the origin making a $45^{\circ}$ line.

Assuming $\lambda$ to be the slope of $u_{j+1}$ against $u_{j}$, equation (7) becomes

$$
\ln (\lambda)=A \Delta t
$$

Expanding equation (9) by substituting for $A$

$$
c_{\mathrm{V}}=\frac{-4 H^{2}}{\pi^{2}} \frac{\ln \lambda}{\Delta t}
$$

It is to be noted that equation (10) is very similar to the equation proposed by Asaoka (1978) for settlement data. However, the pore water pressure data should be selected for $U_{z}>50 \%$ for computing $c_{\mathrm{v}}$ for the case of one-dimensional consolidation.

\section{CONSOLIDATION TESTING PROGRAMME}

Laboratory experiments were carried out using the modified one-dimensional consolidation apparatus to capture the dissipation of pore water pressure during consolidation. A miniature sensitive pore pressure sensor was attached to the base of the sample to measure the excess pore water pressure during the consolidation process. Studies have reported that pore water pressure data are significantly influenced by the stiffness of the pore water pressure sensors (e.g. Perlof et al., 1965; Robinson, 1999). Therefore, proper care was taken in selecting the pore pressure sensors to avoid any compliance of the sensors on the pore water pressure data. Figure 1 shows the experimental set-up used for the current investigation. The soil samples used in this study are collected from the suburbs of University of Wollongong and identified as

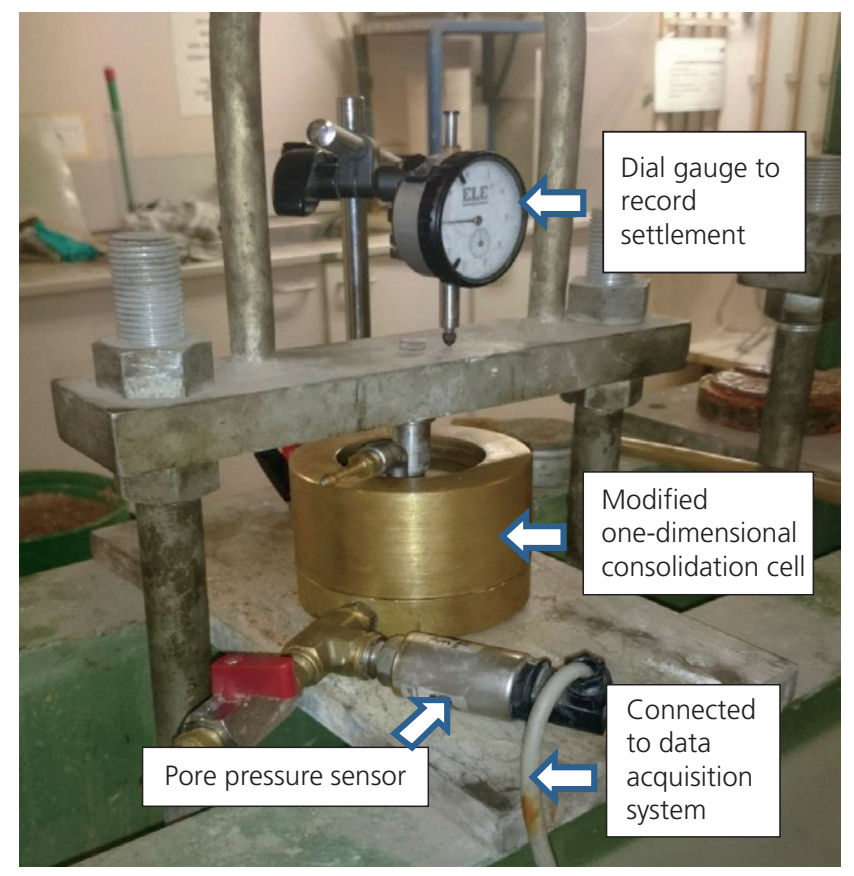

Fig. 1. Experimental test set-up 


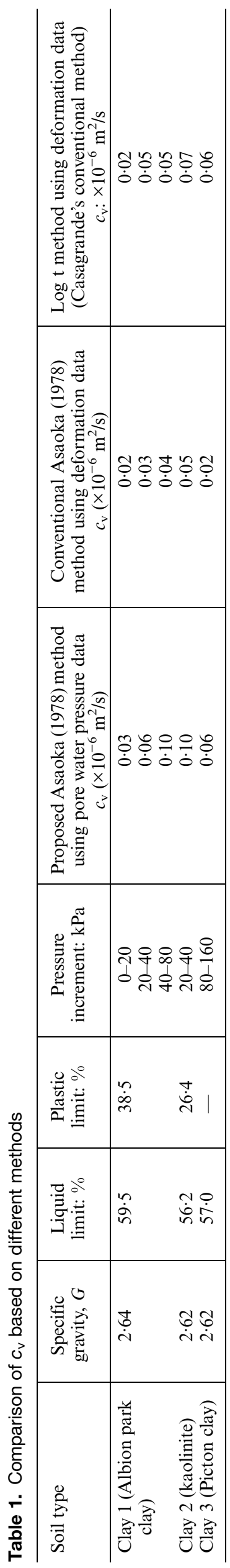

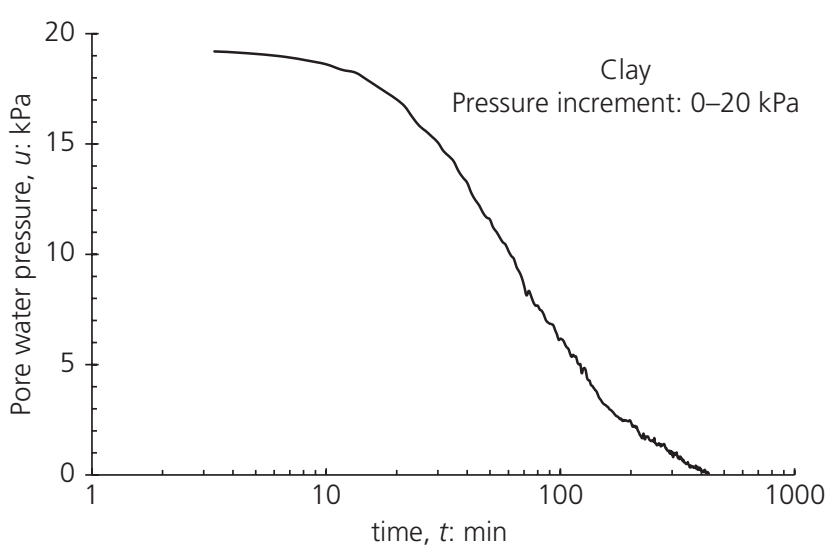

Fig. 2. Typical experimental variation of pore water pressure with time

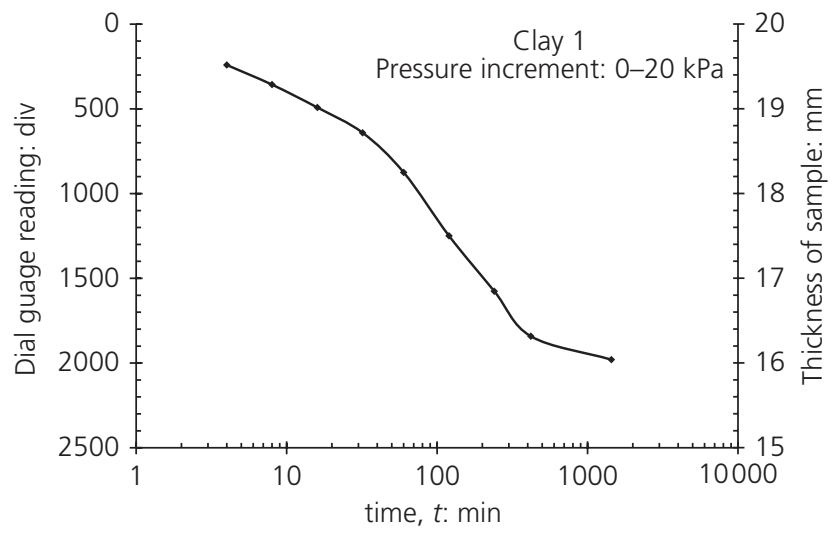

Fig. 3. Typical experimental variation of deformation with time (1 $\operatorname{div}=0.002 \mathrm{~mm}$ )

clay 1 (Albion park clay), clay 2 (kaolinite) and clay 3 (Picton clay). The properties such as specific gravity, liquid limit and plastic limit of the soil samples are tabulated in Table 1. The sensitive pore pressure sensor ( $100 \mathrm{mV}$ output, $0.25 \%$ accuracy and $0.5 \mathrm{~ms}$ response time) is attached to the base of the sample and can measure a very quick response of pore pressure data. The pore pressure sensor was connected to a data acquisition system and was able to capture the data immediately on the application of load; hence, minimising the compliance effect. The soil samples were prepared in the consolidation ring having a dimension of $60 \mathrm{~mm}$ dia. and $20 \mathrm{~mm}$ height. The silicon grease was applied on the sides of the wall of the consolidation ring to minimise friction. The soil was mixed with a predetermined amount of water (1.15 times liquid limit water content) and placed in the consolidation ring. A porous stone and top cap were then placed on the soil sample and loading was carried out by keeping a load increment ratio of one. The deformation and excess pore water pressure corresponding to time were measured simultaneously during the consolidation testing. Figures 2 and 3 show the typical plot of pore water pressure and deformation with $\log t$ for clay 1 , respectively. The initial response of the pore water pressure measuring system indicated that the response of the pore water pressure $(u)$ measured and the applied pressure $\left(\sigma_{n}\right)$ resulted in $u / \sigma_{n} \sim 1$. This further shows the potential of the modified apparatus in capturing pore pressure dissipation during the consolidation stage. It is evident from Fig. 2 that the initial excess pore water pressure developed during the load increment decreases with time. As expected the deformation 


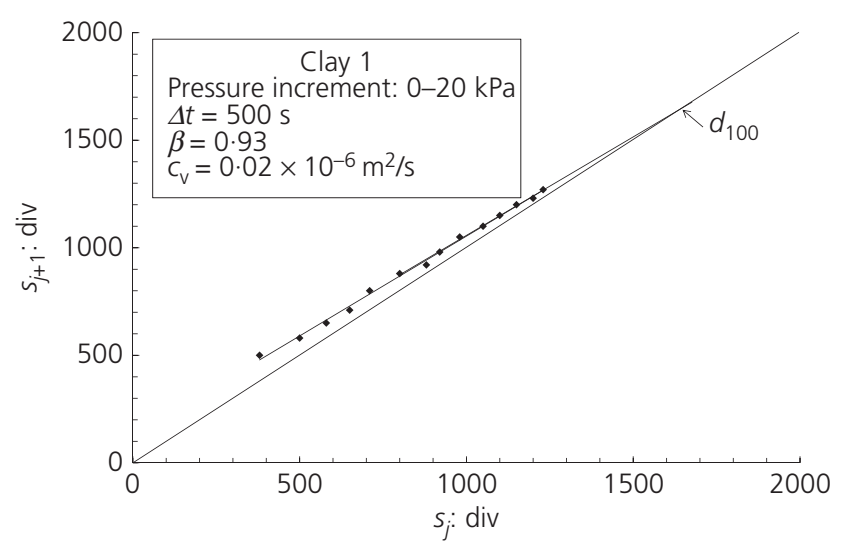

Fig. 4. Plot of $s_{j+1}$ against $s_{j}$

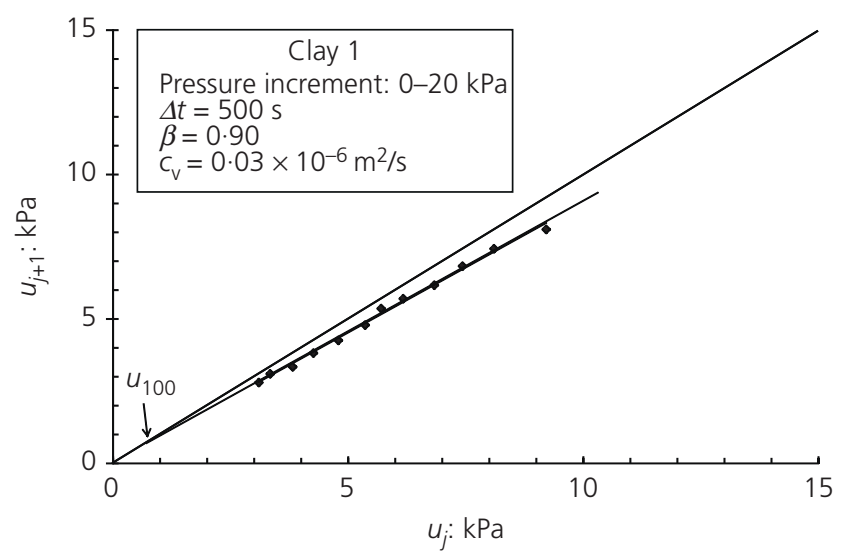

Fig. 5. Plot of $u_{j+1}$ against $u_{j}$

also increases with decrease in the pore water pressure (Fig. 3). Figure 4 shows the plot of $s_{j+1}$ against $s_{j}$ for clay 1 (Albion park clay) for a pressure increment of 0-20 kPa. The conventional Asaoka (1978) method is used to calculate the values of $c_{\mathrm{v}}$ (e.g. Mesri \& Huvaj-Sarihan, 2009; Prakash et al., 2013) for $\Delta t=500 \mathrm{~s}$. The intersection of $45^{\circ}$ line from the origin with the settlement data will give a reading corresponding to EOP consolidation. Figure 5 presents the plot of $u_{j+1}$ against $u_{j}$ for clay 1 for a pressure increment of $0-20 \mathrm{kPa}$. The slope of the line $\lambda$ obtained from Fig. 5 can be used to compute $c_{\mathrm{v}}$ using equation (10) for $\Delta t=500 \mathrm{~s}$. The intersection of a $45^{\circ}$ line from the origin with the pore pressure data will give the pore pressure value at the EOP consolidation point. The deformation reading corresponding to this pore water pressure value will give the deformation at the EOP consolidation $\left(d_{100}\right)$.

\section{DISCUSSIONS}

Table 1 shows some typical results of $c_{\mathrm{v}}$ computed from the pore pressure data using modified Asaoka (1978) method along with the conventional $\log t$ method proposed by Casagrande \& Fadum (1940) and that by Asaoka (1978). It is evident that the $c_{\mathrm{v}}$ values computed based on the pore water pressure data are slightly higher than the values computed from log $t$ and Asaoka (1978) method using the deformation data. The lower value of $c_{\mathrm{v}}$ observed from the deformation analysis is mainly due to the influence of secondary compression (e.g. Sridharan et al., 1995) during consolidation. However, the values of $c_{\mathrm{v}}$ from the deformation data using conventional Asaoka (1978) method show

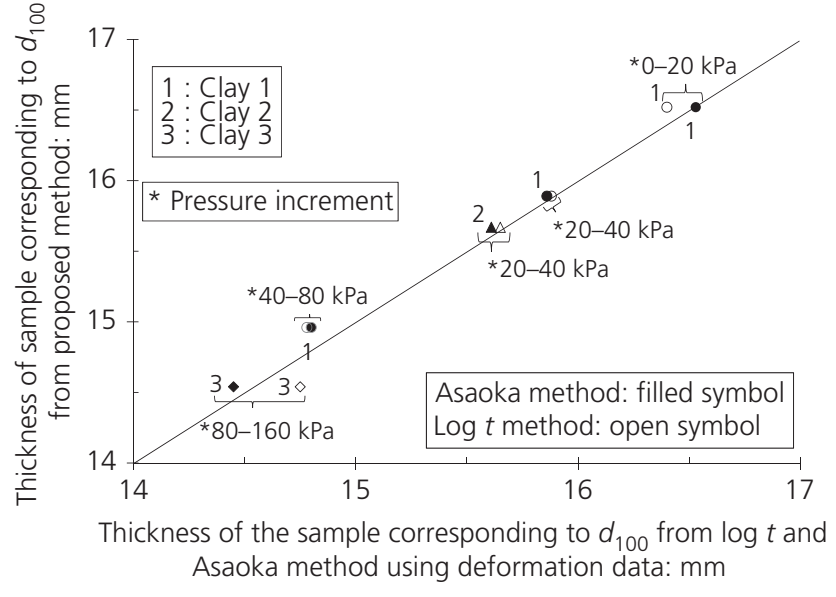

Fig. 6. Comparison of $d_{100}$ obtained from the proposed method with those obtained from the conventional Asaoka (1978) and $\log t$ methods

a close relationship with the conventional $\log t$ method, which is in agreement with the results reported by Prakash et al. (2013). Figure 6 shows the variation of sample thickness corresponding to $d_{100}$ (EOP) computed from the proposed method compared with the Asaoka (1978) and $\log t$ methods. Even though there is a marked difference in the $c_{\mathrm{v}}$ values from pore pressure data and deformation data, there is practically no difference in the EOP values computed from these methods (Fig. 6). It is important to note that Mikasa's theory follows a different law for excess pore water pressure compared with the classical Terzaghi's theory. However, the void ratio-pressure relationship can be taken as linear for any pressure increment applied in the tests. The determination of $c_{\mathrm{v}}$ carried out for particular load increments will not significantly influence the results. Moreover, Asaoka's (1978) method overestimates the values of $c_{\mathrm{v}}$ for $U_{z}<50 \%$ for the case of one-dimensional consolidation. On the contrary, Asaoka's (1978) method is applicable to the entire time interval $\left(U_{z}=0-100 \%\right)$ for radial consolidation.

\section{RECOMMENDED PROCEDURE}

- Select a series of $u_{1}, u_{2}, u_{3}, \ldots, u_{j}, u_{j+1}, \ldots$ corresponding to times $t_{1}, t_{2}, t_{3}, \ldots, t_{j}, t_{j+1}, \ldots$ such that $t_{j+1}-t_{j}$ is a constant for $U>50 \%$.

- Plot $u_{j+1}$ against $u_{j}$ such as to obtain a straight line.

- The slope of the straight line $(\lambda)$ can be used to compute the value of $c_{\mathrm{v}}$ using equation (10).

- Draw a $45^{\circ}$ line through the origin to intersect the $u_{j+1}$ against $u_{j}$ line. The point of intersection will give the pore water pressure at the end of primary consolidation $\left(u_{100}\right)$.

- The $u_{100}$ obtained in the earlier step can be compared with the corresponding deformation values to obtain the deformation at the EOP consolidation $\left(d_{100}\right)$.

\section{CONCLUSIONS}

In this paper, an extended Asaoka (1978) method has been presented on the determination of coefficient of consolidation and EOP consolidation from pore water pressure data. A simple algebraic deduction was carried out for developing a graphical procedure to evaluate $c_{\mathrm{v}}$ from the pore water pressure data. Laboratory experiments were also carried out on a modified consolidation apparatus capturing the pore pressure data using a very sensitive pore pressure sensor. The deformation and pore pressure data were recorded simultaneously using a dial gauge and data acquisition system, 
respectively. The $c_{\mathrm{v}}$ values obtained from the pore water pressure analysis using the modified Asaoka (1978) method will predict more realistic values compared with deformation data analysis as the latter is influenced by initial and secondary compressions. However, the EOP computed from pore water pressure and deformation data shows very close agreement.

\section{ACKNOWLEDGEMENT}

The first author thanks Mr Arash Abedpour for providing the laboratory experimental data for the present analysis.

\section{REFERENCES}

Asaoka, A. (1978). Observational procedure of settlement prediction. Soils Found. 18, No. 4, 87-101.

Casagrande, A. \& Fadum, R. E. (1940). Notes on soil testing for engineering purposes. Soil Mechanics Series, vol. 8. Cambridge, MA, USA: Harvard Graduate School of Engineering, Harvard University.

Gibson, R. E. (1963). An analysis of system flexibility and its effect on time-lag in pore water pressure measurements. Géotechnique 13, No.1, 1-11, http://dx.doi.org/10.1680/geot.1963.13.1.1

Mesri, G. \& Huvaj-Sarihan, N. (2009). The Asaoka method revisited. Proceedings of the 17th international conference on soil mechanics and geotechnical engineering, Alexandria, Egypt, vol. 1, pp. 131-134.

Northey, R. D. \& Thomas, R. F. (1965). Consolidation test pore pressures. Proceedings of the 6th international conference on soil mechanics and foundation engineering, Montreal, vol. 1, pp. 323-327.

Olson, R. E. (1986). State of the art: consolidation testing. In Consolidation of soils: testing and evaluation (eds) R. N. Yong \& F. C. Townsend), ASTM STP 892, pp. 7-70. West Conshohocken, PA, USA: American Society for Testing and Materials.

Parkin, A. K. (1978). Coefficient of consolidation by the velocity method. Géotechnique, 28, No. 4, 472-474, http://dx.doi.org/ 10.1680/geot.1978.28.4.472.

Perlof, W. H., Nair, K. \& Smith, J. G. (1965). Effect of measuring system on pore water pressures in the consolidation test.
Proceedings of the 6th international conference on soil mechanics and foundation engineering, Montreal, vol. 1, pp. 338-341.

Prakash, K., Sridharan, A. \& Sheshashayana, M. (2013). Appraisal of observational method for consolidation analysis. Proc. Instn Civ. Engrs - Geotech. Engng 167, No. 6, 518-525, http://dx.doi. org/10.1680/geng.13.00006.

Robinson, R. G. (1999). Consolidation analysis with pore pressure measurements. Géotechnique 49, No. 1, 127-132, http://dx.doi. org/10.1680/geot.1999.49.1.127.

Robinson, R. G. \& Allam, M. M. (1996). Determination of coefficient of consolidation from early stage of log t plot. Geotech. Test. J. 19, No. 3, 316-320.

Robinson, R. G. \& Soundara, B. (2008). Coefficient of consolidation from midplane pore pressure measurements. Int. J. Geotech. Engng 2, No. 4, 417-423.

Sonpal, R. C. \& Katti, R. K. (1973). Consolidation analysis with pore pressure measurements. Proceedings of the 8th international conference on soil mechanics and foundation engineering, Moscow, vol. 1.2, 385-388.

Sridharan, A. \& Prakash, K. (1993). $\delta-t / \delta$ method for the determination of coefficient of consolidation. Geotech. Test. J., ASTM 16, No. 1, 131-134.

Sridharan, A. \& Prakash, K. (1997). The $\log \delta-\log t$ method for the determination of coefficient of consolidation. Proc. Instn Civ. Engrs - Geotech. Engng 125, No. 1, 27-32, http://dx.doi.org/ 10.1680/igeng.1997.28994.

Sridharan, A. \& Prakash, K. (1998). Determination of coefficient of consolidation: user friendly approach. Ground Engng Mag. Br. Geotech. Soc. 31, No. 2, 30-32.

Sridharan, A., Murthy, N. S. \& Prakash, K. (1987). Rectangular hyperbola method of consolidation analysis. Géotechnique 37, No. 3, 355-368, http://dx.doi.org/10.1680/geot.1987.37. 3.355 .

Sridharan, A., Prakash, K. \& Asha, S. R. (1995). Consolidation behaviour of soils. Geotech. Test. J. 18, No. 1, 58-68.

Tan, S. A. \& Chew, S. H. (1996). Comparison of the hyperbolic and Asaoka observational method of monitoring consolidation with vertical drains. Soils Found. 36, No. 3, 31-42.

Taylor, D. W. (1948). Fundamentals of soil mechanics, New York: Wiley, pp. 238-242.

Whitman, R. V., Richardson, A. M. \& Healy, K. A. (1961). Time-lags in pore pressure measurements. Proceedings of the 5th ICSMFE, Paris, vol. 1, pp. 407-411. 